\title{
Study on Shenyang's Vacant Commodity Housing Based on the Non-equilibrium of Supply and Demand
}

\author{
Xijing QI \\ Department of Resource and Civil Engineering, \\ Northeastern University (NEU), \\ Shenyang, China \\ e-mail: qixijing63@163.com
}

\author{
Xiaoqiang LI \\ Department of Resource and Civil Engineering, \\ Northeastern University (NEU), \\ Shenyang, China \\ e-mail:18704065705@163.com
}

\author{
Yuxin ZHOU \\ Huaqiang Gold Corridor City Plaza Real Estate Co., Ltd \\ Shenyang, China \\ e-mail: zyxjttysys@sina.com
}

\begin{abstract}
Since twentieth Century, the real estate in Shenyang has achieved rapid growth, with the issue of commodity housing vacancy. Considering the difference between China's current algorithm and international algorithm, as well as the market under the non-equilibrium of supply and demand, the international standard for vacancy rate can not be directly applied to China. Firstly, the article reviews the vacancy situation of commercial housing in Shenyang, and determines the suitable range of vacancy rate for commercial and commodity housing in China by revising main differences between domestic and foreign vacancy rate. Then, the article calculates non-equilibrium degree of Shenyang's real estate market by non-equilibrium model, and evaluates the suitability of Shenyang's vacant commodity housing under the nonequilibrium of supply and demand. Finally, it proposes measures of vacant commodity housing from the perspective of the government and developers.
\end{abstract}

Keywords-component; vacancy rate; suitable range; nonequilibrium theory; evaluation

\section{INTRODUCTION}

The vacancy rate is an important index to measure and monitor the performance of market, attracting much attention. At present, there are differences between domestic and foreign vacancy rate because of statistical differences and imperfect data collection, which leads to differences of suitable range for vacancy rate. The current mainstream view thinks that China's suitable vacancy rate ranges from $5 \%$ to $14 \%$, without the support of theoretical basis.

In this article, we determine China's suitable range of vacancy rate for commercial and commodity housing according to main differences between domestic and foreign vacancy rate. Taking Shenyang as an example, we evaluate the suitable level of vacant commodity housing under the non-equilibrium of supply and demand. According to evaluation results, measures of Shenyang's vacant commodity housing are put forward to promote a sustainable development of real estate market.

\section{REVIEW OF VACANT COMMERCIAL HOUSING IN SHENYANG}

\section{A. Concept of Vacant Commercial Housing}

Vacant commercial housing in China refers to the commercial housing under completion of acceptance and delivery conditions, which has not yet been sold or leased after initial registration within a certain period of time [1].

\section{B. Current Algorithm of Vacancy Rate}

Commercial housing vacancy rate reflects the pattern of supply and demand for real estate market, and measures the health of market. Due to the lack of basic data and difficulties on specific operation, Chinese commercial housing vacancy rate refers to the ratio of current vacant area and completion area for the last three years [2]. The current algorithm of vacancy rate is shown in Equation (1):

$$
R v_{i}=\frac{V_{i}}{S_{i}}(i=0,1)
$$

In the formula, $V_{0}, V_{1}$ respectively refers to vacant area of commercial housing and commodity housing; $S_{0}, S_{1}$ respectively refers to completion area of commercial housing and commodity housing for the last three years; $R v_{0}, R v_{1}$ respectively refers to vacancy rate of commercial housing and commodity housing.

\section{Review of Vacancy situation for Shenyang's Commercial housing}

According to relevant data from 2004 to 2014 in "Shenyang statistical yearbook" [3] and Equation (1), we obtain the vacancy situation in recent years with detailed data shown in Table 1 . We find vacant area of commercial housing and commodity housing experience a decline every few years, reflecting a process of inventory digestion. With 
the increase in area completed from 2004 to 2014, vacancy rate of commercial housing and commodity housing respectively increases by 3.05 times and 2.68 times. From the view of vacancy rate, the vacancy level of Shenyang's commercial housing and commodity housing are a little high in 2004 and 2005. Furthermore, vacancy rate of commercial housing and commodity housing are both within 25\% from 2006 to 2014, while the real estate market in Shenyang gets a stable and rapid development. It should be noted that the sudden rise in vacancy rate because of the reversal of supply and demand for real estate market in 2013, meaning the risk of high inventory in the short term in Shenyang.

TABLE I. Vacancy rate of commercial housing and commodity housing in Shenyang from 2004 to 2014

\begin{tabular}{|c|c|c|c|c|}
\hline Time & $\begin{array}{c}\text { Vacancy } \\
\text { area of } \\
\text { commercial } \\
\text { housing } \\
\left(10000 \mathrm{~m}^{2}\right)\end{array}$ & $\begin{array}{c}\text { Vacancy } \\
\text { area of } \\
\text { commodity } \\
\text { housing } \\
\left(10000 \mathrm{~m}^{2}\right)\end{array}$ & $\begin{array}{c}\text { Vacancy } \\
\text { rate of } \\
\text { commercial } \\
\text { housing } \\
(\%)\end{array}$ & $\begin{array}{c}\text { Vacancy } \\
\text { rate of } \\
\text { commodity } \\
\text { housing } \\
(\%)\end{array}$ \\
\hline 2004 & 447.1 & 386.6 & 34.4 & 34.8 \\
\hline 2005 & 488.6 & 392.2 & 27.8 & 25.7 \\
\hline 2006 & 461.3 & 319.1 & 18.8 & 14.9 \\
\hline 2007 & 453.9 & 306.3 & 14.9 & 11.5 \\
\hline 2008 & 540.5 & 360.7 & 15.3 & 11.9 \\
\hline 2009 & 616.0 & 413.9 & 16.4 & 13.0 \\
\hline 2010 & 572.6 & 404.6 & 14.8 & 12.5 \\
\hline 2011 & 631.0 & 473.4 & 15.9 & 14.5 \\
\hline 2012 & 701.9 & 533.7 & 15.0 & 14.1 \\
\hline 2013 & 1022.0 & 796.8 & 18.8 & 18.3 \\
\hline 2014 & 1221.6 & 889.5 & 22.2 & 19.9 \\
\hline
\end{tabular}

\section{Suitable Range OF VACANCy Rate For COMMERCIAL AND COMMODITY HOUSING IN CHINA}

\section{A. Delineation Basis of Suitable Range}

1) Correction for the difference of available rental and sale area and completed area:

International vacancy rate is calculated on the basis of available rental and sale area, while the vacancy rate in China is calculated on the basis of completed area. Generally, unavailable rental and sale area accounts for about $12 \%$ of completed area [4], and the vacancy area subsumed into available rental and sale area is about $50 \%$ of completed area. Combined with above two effects, the vacancy level in China is nearly $30 \%$ higher than international vacancy level. In general, the corrective coefficient for the difference of available rental and sale area and completed Area $\left(K_{1}\right)$ ranges from 0.25 to 0.30 .

2) Correction for vacant time:

According to rational inventory theory, the commercial housing with vacant time in one year, is regarded as a rational inventory under the condition of market economy.
However in China, the commercial housing with vacant time in a year is included into vacant commercial housing scope, leading to the expansion of vacancy crisis. In fact, we should use the commercial housing with vacant time over one year to measure vacancy rate. According to estimating, the number of commercial housing with vacant time in one year is about $30 \%$ to $40 \%$ of the total number of vacant commercial housing in China, and China's vacancy rate is about $45 \%$ to $65 \%$ higher than that of foreign countries. In general, the corrective coefficient for vacant time $\left(K_{2}\right)$ ranges from 0.40 to 0.70 .

3) Correction for pre-sale system:

At present, there is pre-sale system of commercial housing in China. Although vacant housing should be completed housing, China's vacant housings inevitably mixed with some forward delivery housings, and domestic vacancy rate is higher than foreign level. Further, it is estimated the ratio of forward delivery housing to existing housing is between two and four. Considering a $10 \%$ to $20 \%$ ratio of forward delivery housing regarded as vacant housing, domestic vacancy rate is $20 \%$ to $60 \%$ higher than that of foreign countries. In general, the corrective coefficient for pre-sale system $\left(K_{3}\right)$ ranges from 0.20 to 0.60 .

4) Correction for coordination of three-level market:

Whether the total amount, or the proportion, the impact of stocking housing exchanging market and rental market has not been ignored with increasing stocking housing. The suitable range of vacancy rate can be relatively relaxed [1]. In general, the corrective coefficient for coordination of Three-level market $\left(K_{4}\right)$ ranges from 0.10 to 0.30 .

5) Correction for the effect of economic cycle:

As we know, real estate industry is closely related to national economic development, and affected by national economic cycle. When national economy develops rapidly, vacancy rate is relatively low because of large demand for housing. Conversely, when national economy development is in a low speed, vacancy rate is relatively high because of low demand for housing. According to the correction coefficient given by Xijing Qi, this paper considers the suitable range of vacancy rate can be relaxed. In general, the corrective coefficient for the effect of economic cycle $\left(K_{5}\right)$ ranges from -0.05 to -0.15 as national economy develops rapidly, but ranges from 0.05 to 0.15 as national economy development is in a low speed.

According to international suitable vacancy rate $\left(R_{0}\right)$ ranging from $5 \%$ to $10 \%$, we obtain China's suitable vacancy rate of commercial housing $\left(R_{1}\right)$ by revising main differences between domestic and foreign vacancy rate. The specific revised formula is given in Equation (2):

$$
R_{1}=R_{0} \cdot\left(1+K_{1}+K_{2}+K_{3}+K_{4}+K_{5}\right)
$$

Meanwhile, as the absolute subject of commercial housing, commodity housings usually account for more than $70 \%$ of all commercial housings. Therefore, the vacancy rate of commodity housing is more stable and lower than that of commercial housing. We obtain the suitable vacancy rate of commodity housing $\left(R_{2}\right)$ based on a reduction treatment of 
$R_{1}$. The specific calculation formula is given in Equation (3):

$$
R_{2}=0.85 \times R_{1}
$$

\section{B. Determination of Suitable Range}

According to delineation basis of suitable range and international suitable vacancy rate $\left(R_{0}\right)$ ranging from $5 \%$ to $10 \%$, this paper respectively gives the suitable range of vacancy rate for commercial and commodity housing based on China's specific condition, which is found in Table 2.

TABLE II. The suitable range of vacancy rate for commercial and commodity housing in China

\begin{tabular}{|c|c|c|}
\hline Index type & Suitable range (\%) & Remarks \\
\hline $\begin{array}{c}\text { Commercial housing } \\
\text { vacancy rate }\left(R_{1}\right)\end{array}$ & $12.0-23.5$ & \multirow{2}{*}{$\begin{array}{c}K_{1}=0.25, K_{2}=-0.05, \\
K_{3}=0.20, \\
K_{4}=0.30, K_{5}=0.60\end{array}$} \\
\hline $\begin{array}{c}\text { Commodity housing } \\
\text { vacancy rate }\left(R_{2}\right)\end{array}$ & $10.0-20.0$ & \\
\hline
\end{tabular}

IV. EVALUATION ON THE SUITABILITY OF SHENYANG'S VACANT COMMODITY HOUSING UNDER NON-EQUILIBRIUM OF SUPPLY AND DEMAND

\section{A. Non-equilibrium Model of Supply and Demand}

\section{1) Non-equilibrium theory and model:}

Non-equilibrium theory thinks that equilibrium is the most efficient state, but disequilibrium is a normal state. In general, non-equilibrium model includes minimum principle equation, CES type exponential equation and hyperbolic equation of polymerization [5-8]. In fact, hyperbolic equation is closer to the reality of real estate market, and this paper adopts hyperbolic equation to study real estate market.

2) Establishment of non-equilibrium model of supply and demand:

The real estate market is influenced by a number of factors, such as real estate price, national economic development level, per capita disposable income and other factors [9]. Usually, real estate prices, national economic development level and per capita disposable income affect the demand of real estate market. While real estate price, national economic development level, economic policy and production investment affect the supply of real estate market. As relational data are limited, this article finally selects five factors to determine the model of supply and demand, including marketable housing area sold, per capita GDP, the average selling price of commercial housing, fixed assets investment in real estate, and per capita disposable income [10].

The demand equation established is as follows:

$$
D=\alpha_{1} P+\alpha_{2} P G+\alpha_{3} R+\mu_{1}
$$

The supply equation established is as follows:

$$
S=\beta_{1} P+\beta_{2} P G+\beta_{3} I+\beta_{4} R+\mu_{2}
$$

The trading volume equation is as follows:

$$
Q \leq \operatorname{MIN}(D, S)
$$

Non-equilibrium degree $Z$ is shown in Equation (7):

$$
Z=\frac{(D-S)}{Q}
$$

In above formulas, $D$ refers to the total amount of effective demand, $S$ refers to the total amount of effective supply, $Q$ is trading volume, and $Z$ is non-equilibrium degree. In addition, $P G$ refers to per capita GDP, $P$ refers to the average selling price of commercial housing, $I$ refers to the fixed assets investment in real estate, $R$ refers to per capita disposable income, $\alpha$ and $\beta$ are model parameters, $\mu$ is random error term.

\section{B. Quantitative Analysis on the Supply and Demand of Shenyang's Real Estate Market}

In this article, it is assumed that the market is in equilibrium. According to relational data 2004 to 2014 in "Shenyang statistical yearbook", we use Eview6.0 to estimate relational parameters, and fitting non-equilibrium models are as follows:

$$
\begin{gathered}
D=-0.445 P+0.127 P G-0.239 R+1197.397 \\
S=-0.642 P+0.247 P G-2.776 I-0.324 R+451.853(9)
\end{gathered}
$$

The fitting degrees of above two equations are respectively 0.929 and 0.958 , which are relatively good. Although the price of the two equations has not passed by $\mathrm{T}$ test, every equation has passed $\mathrm{F}$ and DW test, which does not have an impact on subsequent analysis. Finally, according to the fitted model and history data, we get nonequilibrium degree of the real estate market in Shenyang in recent years. The detailed data are shown in Table 3.

According to the national non-equilibrium cordon delineated by Langchao $\mathrm{Ji}$ and the development of Shenyang's real estate market, the non-equilibrium cordon of Shenyang's real estate market is also set to $10 \%$. When the absolute value of non-equilibrium degree is less than $10 \%$, the level of supply and demand is normal. Conversely, the level of supply and demand is abnormal as the absolute value of the non equilibrium degree is more than $10 \%$. From Table 3, it can be seen that Shenyang's real estate market maintains a basic balance between supply and demand in recent years. In addition, the market supply is less than the market demand in 2004, and the market supply is slightly greater than the market demand in 2007. 
TABLE III.

Non-equilibrium degree of the real estate market in Shenyang from 2004 to 2014

\begin{tabular}{|c|c|c|c|c|}
\hline Time & $\begin{array}{c}D \\
\left(10000 \mathrm{~m}^{2}\right)\end{array}$ & $\begin{array}{c}S \\
\left(10000 \mathrm{~m}^{2}\right)\end{array}$ & $\begin{array}{c}Q \\
\left(10000 \mathrm{~m}^{2}\right)\end{array}$ & $\mathrm{Z}$ \\
\hline 2004 & 816.1 & 670.3 & 670.3 & 0.2175 \\
\hline 2005 & 926.0 & 914.5 & 914.5 & 0.0126 \\
\hline 2006 & 1141.3 & 1248.4 & 1141.3 & -0.0939 \\
\hline 2007 & 1248.8 & 1411.1 & 1248.8 & -0.1300 \\
\hline 2008 & 1408.2 & 1380.2 & 1380.2 & 0.0203 \\
\hline 2009 & 1614.4 & 1569.4 & 1569.4 & 0.0287 \\
\hline 2010 & 1784.9 & 1679.1 & 1679.1 & 0.0630 \\
\hline 2011 & 2213.7 & 2360.4 & 2213.7 & -0.0663 \\
\hline 2012 & 2269.9 & 2288.8 & 2269.9 & -0.0083 \\
\hline 2013 & 2433.9 & 2317.3 & 2317.3 & 0.0503 \\
\hline 2014 & 1499.0 & 1535.9 & 1499.0 & -0.0246 \\
\hline
\end{tabular}

C. Suitability of Shenyang's Commodity Housing under the Non- equilibrium of Supply and Demand

1) Corrections for suitable range under the nonequilibrium of supply and demand:

The suitable range of commodity housing vacancy rate refers to the suitable vacancy level shown in a normal real estate market, and we should correct the suitable range under the abnormal level of supply and demand. Usually, the vacancy rate level is relatively high as the supply is greater than the demand, and the suitable range should be slightly improved. Conversely, the result is contrary. According to non-equilibrium analysis results of Shenyang's real estate market, corrections for suitable range under the nonequilibrium of supply and demand are as follows:

$$
\begin{gathered}
R_{2}{ }^{\prime}=R_{2} \cdot[1-(Z+0.1)] \quad(\mathrm{Z} \leq-0.1) \\
R_{2}{ }^{\prime}=R_{2} \quad(-0.1 \leq \mathrm{Z} \leq 0.1) \\
R_{2}{ }^{\prime}=R_{2} \cdot[1-(Z-0.1)] \quad(\mathrm{Z} \geq 0.1)
\end{gathered}
$$

In the formula, $R_{2}{ }^{\prime}$ refers to the corrective suitable range under the non-equilibrium of supply and demand.

2) Evaluation on the suitability of Shenyang's vacant commodity housing:

According to the vacancy situation of Shenyang's commodity housing in recent years and the corrective suitable range under the non-equilibrium of supply and demand, we evaluate the suitability of Shenyang's vacant commodity housing in recent years. Detailed results are shown in Table 4.
TABLE IV. Evaluation on the suitability of Shenyang's commodity housing vacancy rate in recent years

\begin{tabular}{|c|c|c|c|c|}
\hline Time & $\begin{array}{c}\text { Non- } \\
\text { equilibrium } \\
\text { degree } Z\end{array}$ & $\begin{array}{c}\text { Corrective } \\
\text { suitable } \\
\text { range } \\
R_{2}^{\prime}(\%)\end{array}$ & $\begin{array}{c}\text { Vacancy } \\
\text { rate of } \\
\text { commodity } \\
\text { housing } \\
(\%)\end{array}$ & $\begin{array}{c}\text { Evaluation } \\
\text { of vacancy } \\
\text { level }\end{array}$ \\
\hline 2004 & 0.2175 & $8.8-17.7$ & 34.81 & High \\
\hline 2005 & 0.0126 & $10.0-20.0$ & 25.72 & $\begin{array}{c}\text { Slightly } \\
\text { high }\end{array}$ \\
\hline 2006 & -0.0939 & $10.0-20.0$ & 14.92 & Suitable \\
\hline 2007 & -0.1300 & $10.3-20.6$ & 11.51 & Suitable \\
\hline 2008 & 0.0203 & $10.0-20.0$ & 11.89 & Suitable \\
\hline 2009 & 0.0287 & $10.0-20.0$ & 13.00 & Suitable \\
\hline 2010 & 0.0630 & $10.0-20.0$ & 12.47 & Suitable \\
\hline 2011 & -0.0663 & $10.0-20.0$ & 14.52 & Suitable \\
\hline 2012 & -0.0083 & $10.0-20.0$ & 14.09 & Suitable \\
\hline 2013 & 0.0503 & $10.0-20.0$ & 18.28 & Suitable \\
\hline 2014 & -0.0246 & $10.0-20.0$ & 19.85 & Suitable \\
\hline
\end{tabular}

From Table 4, we can find the vacant level of Shenyang's commodity housing is basically in a controllable range from 2004 to 2014. Meanwhile, the evaluation result shows a high vacancy level in 2004 and a slightly high vacancy level in 2005, which may be caused by the emergence of inflection point in a new round of market cycle. In addition, we also find the rapid growth of vacant level from the beginning of 2013 and a relatively high vacancy level closing to the upper limit of suitable range in 2014. Through the analysis, the relatively high vacancy level in 2014 may be influenced by the reversal of supply and demand. We should pay more attention to it, and prevent the risk of rising vacancy level.

\section{MEASURES OF VACANT COMMODITy HoUSING}

The commodity housing, a foundation-level product, inevitably appears abnormal vacant level under the condition of market economy. Therefore, the government and developers should take appropriate measures to control vacant level and promote the steady and healthy development of the real estate market in Shenyang.

\section{A. Establishment of Scientific and Improved Market Monitoring systems}

The government should implement the main responsibility and establish scientific and improved market monitoring systems, including monitoring important vacancy indicators and making a correct assessment on the current situation of market. The government should also release market information to the public in a timely manner, enabling developers to accurately understand the operation of market and to properly build the commodity housing in Shenyang. 


\section{B. Establishment a Scientific Mechanism of Land Supply}

Taking into account development needs of Shenyang city, the government should balance the development of whole city and implement differential land supply in accordance with the principle of stressing focal points and the differential treatment. Moreover, the government should also control the size of the land transfer, not only to meet the demand for land, but also to avoid the land vacancy and wasted. In a word, controlling the total amount of vacant commercial housing is a very good measure.

\section{Improvement of Housing Quality and Innovation}

In the face the fluctuation of supply and demand in real estate market, developers should improve the quality of housing and strengthen product innovation to meet people's growing needs of life, including promoting the use of medical elevator and residential green buildings etc.

\section{Guidance of Public Opinion and Consumption Concept}

The government should strengthen propaganda work and correctly guide market expectations, to guide people's rational view of real estate market. In addition, the government should also encourage residents to establish the correct concept of housing consumption, which is intended to improve the ecological chain of housing consumption market.

\section{ACKNOWLEDGMENT}

In this paper, revising main differences between domestic and foreign vacancy rate, we firstly determine the suitable range of vacancy rate for commodity housing in China which ranges from $10.0 \%$ to $20.0 \%$. Then, we calculate the nonequilibrium degree of Shenyang's real estate market by nonequilibrium theory, and evaluate the suitability of Shenyang's vacant commodity housing under the non-equilibrium of supply and demand. Through the analysis of evaluation results, we find a high vacancy level in 2004 and a slightly high vacancy level in 2005, and we should also pay attention to the vacancy level which is close to the upper limit of suitable range in 2014. In the end, from aspects of market monitoring system, mechanism of land supply, housing quality and guidance of people's consumption, we propose measures of vacant commodity housing for the government and developers.

\section{REFERENCES}

[1] Xijing Qi. The Crisis and Its Prevention for Unsold Commercial Houses [D], Shenyang: Northeastern University.2007: 48-93.

[2] Yousong Wang, Tiehong Lin , Fang Wang et al. Calculation and analysis of Guangzhou commercial housing vacancy rate [J]. Construction Economy. 2008(3): 35-37.

[3] Shenyang municipal bureau of statistics. Shenyang statistical yearbook [M]. China statistics press. 2004-2014.

[4] Yuanhao Li. Commercial housing vacancy rate level and Countermeasures [J]. Statistical research, 1999.

[5] Fair R C, Jaffee D W. Methods of estimation for markets in disequilibrium [J]. Econometrica, 1992, 40(3): 497-514.

[6] Anas A, Hedonic E S J. Analysis of housing market in disequilibrium [J]. Journal of Urban Economics, 2006, 15(1):87-106.

[7] Mary R. Housi market disequilibrium: an examination of housingmarket price and stock dynamics 1967-1998 [J]. Journal of Housing Economics, 2004, 139(2): 120-135.

[8] Yong T. Segmentation, adjustment and disequilibrium, housing economics and public policy [J]. Mass: Blackwell Science Ltd. 2002: $38-55$.

[9] Bin Que. The non-equilibrium analysis with supply and demand of the real estate market [D]. Southwestern University of Finance and Economics, 2010: 54-63.

[10] Xijing Qi, Jie Zhang, Jiaojiao Qin et al. Analysis and Countermeasures for Non-equilibrious Development of Real Estate Market of Liaoning Province [J]. Journal of Northeastern University(Natural Science). 2013(34): 733-734. 